\title{
Influence of the Nano-micro Structure of the Surface on Bacterial Adhesion
}

\author{
Carolina Díaz, María Cecilia Cortizo a, Patricia Laura Schilardi, Sandra Gabriela Gómez de Saravia, \\ Mónica Alicia Fernández Lorenzo de Mele ${ }^{\mathrm{a}, \mathrm{c}^{*}}$ \\ anstituto de investigaciones Fisiocoquímicas Teóricas y aplicadas - INIFTA, \\ Facultad de Ciencias Exactas, Universidad Nacional de La Plata - UNLP, \\ Casilla de Correo, 16, Sucursal, 4, 1900, La Plata, Argentina \\ ${ }^{\mathrm{b}}$ Comisión de Investigaciones Científicas de La Provincia de Buenos Aires - CICPBA, Argentina \\ ${ }^{\mathrm{c}}$ Facultad de Ingeniería, Universidad Nacional de La Plata - UNLP,
} 1900, La Plata, Argentina

Received: August 3, 2006; Revised: November 7, 2006

\begin{abstract}
Biomaterials failures are frequently associated to the formation of bacterial biofilms on the surface. The aim of this work is to study the adhesion of non motile bacteria streptococci consortium and motile Pseudomonas fluorescens. Substrates with micro and nanopatterned topography were used. The influence of surface characteristics on bacterial adhesion was investigated using optical and epifluorescence microscopy, scanning electron microscopy (SEM) and atomic force microscopy (AFM). Results showed an important influence of the substratum nature. On microrough surfaces, initial bacterial adhesion was less significant than on smooth surfaces. In contrast, nanopatterned samples showed more bacterial attachment than the smooth control. It was also noted a remarkable difference in morphology, orientation and distribution of bacteria between the smooth and the nanostructured substrate. The results show the important effect of substratum nature and topography on bacterial adhesion which depended on the relation between roughness characteristics dimensions and bacterial size.
\end{abstract}

Keywords: biofouling, bacterial adhesion, extracellular polymeric material, micro/nanotopography

\section{Introduction}

Reactions at interfaces are very important in biology ${ }^{1}$. Interfaces of medical and industrial interest include bacteria/metal surface. Biofilm- associated cells can be differentiated from their counterparts in solution by the production of an extracellular polymeric material (EPM). Basically, the most remarkable and dangerous attributes of biofilms are their ubiquity and their notorious resistance to being killed by antimicrobial agents ${ }^{2}$. Attachment is a complex process regulated by diverse characteristics of the growth medium, substratum and cell surface. The initial bacterial stages of biofilm formation seem to be influenced by the motility of bacteria. The microcolonies develop into a mature biofilm with an arquitecture that is typically characterized by macrocolonies separated by fluid-filled channels ${ }^{3}$. It is believed that these channels transport nutrients and oxygen to the bacteria and aid in waste removal ${ }^{4,5}$. Surface properties significantly govern the first steps of bacterial adhesion processes. Roughness and surface composition can be modified through appropriate micro/nanofabrication techniques to study the influence of these properties on bacterial adhesion.

Nano/microfabrication techniques enable the researcher to design with nano/micrometer-level control, the biochemical composition and topography of the substrate ${ }^{1,6}$. The aim of this paper was to study the influence of the surface characteristics on the bacterial attachment during the early stages of bacterial biofilms development. Substrates with different roughness, and nanostructurated metals were assayed.

\section{Materials and Methods}

\subsection{Bacteria strains and culture conditions}

To determine bacterial response to the substrates of interest, a consortium of streptococci collected from the oral cavity of several

*e-mail: mmele@inifta.unlp.edu.ar

Article presented at the IV Congresso Latino Americano de Órgãos Artificiais e Biomateriais (COLAOB 2006), August 8 and 11, 2006, Caxambu, MG, Brazil patients with a normal periodontal status were used in the experiments. A pure culture of Pseudomonas fluorescens (P. fluorescens) isolated from an industrial environment was also used to investigate the effect of motility on bacterial attachment. P. fluorescens was maintained in Cetrimide agar at $28^{\circ} \mathrm{C}$. P. fluorescens inoculum was prepared by suspending a Cetrimide agar slant ( 24 hours old) in $2 \mathrm{~mL}$ of sterile nutrient medium. Afterwards, the inoculum was poured into an Erlenmeyer flask containing $300 \mathrm{~mL}$ of the nutrient broth medium and kept on a rotary shaker for 3 hours at $28{ }^{\circ} \mathrm{C}$.

Oral microorganisms collected from the oral cavity were obtained by scraping the gingival area of buccal and lingual tooth surfaces and along the entire fissure of margin of restorations on occlusal surfaces of the patients. Each sample was dispersed by sonication for $10 \mathrm{~s}$ in sterile culture medium. Every 2 months they were completely replaced by new samples obtained from the same patients. The consortium was cultured in Mitis-Salivarius agar medium to isolate the streptococci consortium. Isolated microorganisms were maintained in modified Mitis-Salivarius liquid medium as described elsewhere ${ }^{7}$.

After 24 hours growth, the different substrates were placed into the culture so that a bacterial biofouling could be formed on them. The samples were removed after periods varying from 30 minutes to 2 hours.

\subsection{Substrata}

The substrates used in the experiment were: sheets of Ti polished with emery papers of different grades (320 to 800), Si (plane 100 and rough), and $\mathrm{Cu}$ and $\mathrm{Au}$ (smooth and nanoestructured).

Rough Si showed features of $8 \mu \mathrm{m}$ wide and $2 \mu \mathrm{m}$ deep, measured with AFM (Figure 1). The smooth Si surface was used as control. Ti sheets were polished to different grades with emery paper and then 
etched with $60 \mathrm{~g} / \mathrm{L} \mathrm{HCl}+30 \mathrm{~g} / \mathrm{L} \mathrm{NaF}+20 \mathrm{~g} / \mathrm{L} \mathrm{NaCL}$ solution in order to generate surfaces with different roughness. Nanostructured materials: $\mathrm{Cu}$ and $\mathrm{Au}$ substrates present a nanostructure consisting in channels of $90 \mathrm{~nm}$ height and 900 width (Figure 2). These substrates were prepared according to Schilardi et al. ${ }^{8} . \mathrm{Cu}$ and $\mathrm{Au}$ evaporated films on glass, that present a microlevel smooth structure, were used as controls.

\subsection{Microscopic observations}

Biofilms were observed through optical epifluorescence microscopy. Bacteria were stained with fluorescein diacetate and ethidium bromide. SEM observations of the biofilm were also made. To preserve biological structures, biofilmed metal specimens were fixed in $2 \%$ glutaraldehyde in sterile saliva or in a phosphate buffered medium, dehydrated through an acetone series to $100 \%$ and critical point dried. The effect of substratum topography was also analysed by using a Nanoscope IIIa AFM (Digital Instruments).

\section{Results and Discussion}

The effect of surface composition was analized by comparing initial stages of biofilm formation of smooth $\mathrm{Cu}$ and $\mathrm{Au}$. Results show (Figure $3 \mathrm{a}$ and $3 \mathrm{~b}$ ) that after the same exposure period copper samples show lower bacterial attachment than gold samples. As expected ${ }^{9}$, there was an induction or major conditioning period in copper substrates and bacterial adhesion was lower than on the rest of the materials assayed for the same inmersion periods.

Copper and their alloys present a lower formation of biological deposits (biofouling) due to, probably, toxic characteristics of the $\mathrm{Cu}$ ions (II) coming from the metal dissolution ${ }^{10,11}$. Thus, when the substrate is toxic for the microorganisms, a greater production of EPM than on no toxic samples, such as gold, was observed (Figure 4).

There were several differences in the initial stages of microbial attachment on the smooth and nanostructured surfaces. It was found a slight orientation of $P$. fluorescens into the trench of the nanopatterned surface of copper substratum whereas there was an important alignment of bacteria on gold nano-patterned surface. Motile strains, place themselves easily at trenches and crevices as shown in Figure 5. The formation of biofilms by Pseudomonas has been proposed to occur as a series of regulated steps ${ }^{12}$. First, flagellar mediated motil-

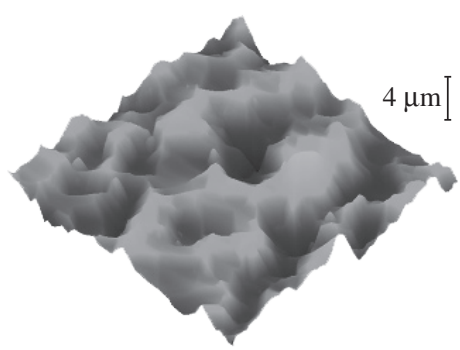

Figure 1. AFM image (contact mode, $50 \times 50 \mu \mathrm{m}^{2}$ ) of rough surface of $\mathrm{Si}$ showing the box-like holes.

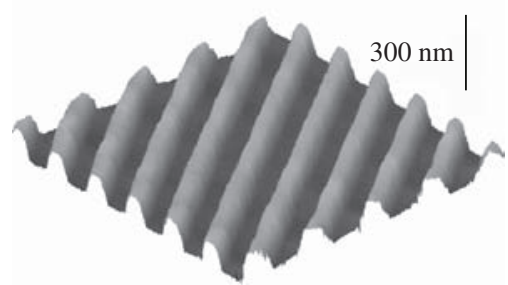

Figure 2. AFM image (contact mode, $10 \times 10 \mu \mathrm{m}^{2}$ ) of $\mathrm{Cu}$ nanoestructured surface. The Au samples present the same superficial features. ity may be required for a bacterium to swim toward a surface and to initiate reversible attachment ${ }^{13}$. A subpopulation of transiently attached bacteria become irreversibly attached to the surface to first form a monolayer, which is followed by migration and the formation of small microcolonies ${ }^{14-18}$. The distribution of bacteria on smooth surfaces was uniform.

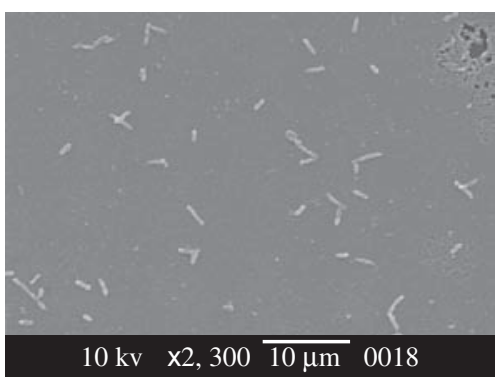

(a)

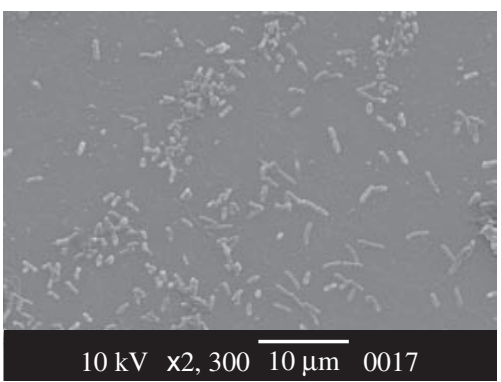

(b)

Figure 3. a) SEM microphotograph of cristalline $\mathrm{Cu}$ surface exposed during 30 minutes to a P. fluorescens culture; and b) SEM microphotograph of cristalline Au surface exposed during 30 minutes to a P. fluorescens culture.

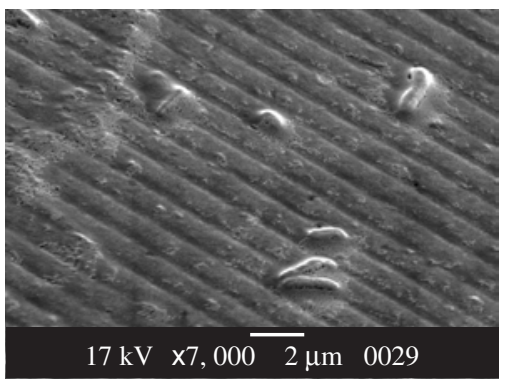

Figure 4. SEM microphotograph of $\mathrm{Cu}$ nanoestructured surface exposed during 30 minutes to $P$. fluorescens culture.

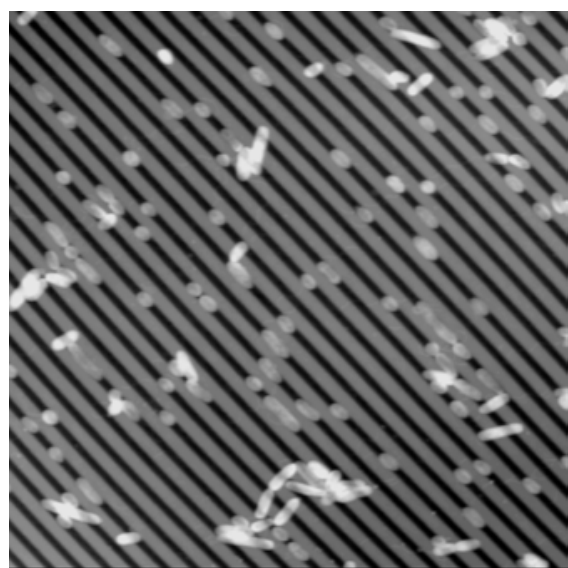

Figure 5. $40 \mu \mathrm{m} \times 40 \mu \mathrm{m}$ contact mode AFM top view image of Au nanostructured surface exposed during 30 minutes to a culture of $P$. fluorescens. 
Most of bacteria placed on the trench were alone and there was no microscopic evidence of production of EPM on the gold nanostructured substrate.

Change in $P$. fluorescens morphology was also noted between the nanostructured surface and the smooth control, as shown in Tables 1 and 2. Importantly, the length of the attached bacteria was shorter than those adhered to the smooth surface. We have measured the bacterial length using AFM images. On gold nanostructured surfaces the average lenght was $1.446 \mu \mathrm{m} \pm 0.120 \mu \mathrm{m}$, while on gold smooth substrate it was $1.996 \mu \mathrm{m} \pm 0.123 \mu \mathrm{m}$. These results were significantly different, showing cell reduction of the size on nanopatterned sample. All data were analysed by standard $t$-tests with statistical differences between means determined at $p<0.05$. In addition, gold nanostructured surface presented more significant bacterial attachment than the control sample.

Assays on micro-rough Ti surfaces showed that $P$. fluorescens attachment was not uniform and follow preferential directions. Figure 6 shows that the Streptococci preferentially attach on the valleys.

The shape of the colonies is markedly affected by the roughness of the surface in the case of streptococci. Observations through epifluorescence microscopy showed that bacteria attached on the valleys of the rough surface and then grew following a row. After longer exposures they presented long and narrow colonies (Figure 7) different from the round shape colonies formed on smooth titanium.

In contrast with results described above related to bacterial attachment on smooth and nanostructurated gold, the surface density of bacteria on smooth $\mathrm{Si}$ was higher than those of microrough samples (Figure $8 \mathrm{a}$ and $8 \mathrm{~b}$ ). Consequently, microroughness and nanostructures seem to play different roles.

Microrough Si presents a surface topography characterized by small boxes of $2 \mu \mathrm{m}$ height and $8 \mu \mathrm{m}$ long as shown in Figure 1 . During the exposure time the boxes are progressively covered by

Table 1. Average size of $P$. fluorescens attached to Au substrates.

\begin{tabular}{lcc}
\hline \multicolumn{1}{c}{$\mathrm{Au}$} & Smooth $(\mu \mathrm{m})$ & Nanostructured $(\mu \mathrm{m})$ \\
\hline Length & 1.996 & 1.446 \\
Variance & 0.123 & 0.120 \\
Diameter & 1.091 & 0.909 \\
Variance & 0.032 & 0.013 \\
\hline
\end{tabular}

Table 2. Average size of $P$. fluorescens attached to $\mathrm{Cu}$ substrates.

\begin{tabular}{lcc}
\hline \multicolumn{1}{c}{ CU } & Smooth $(\mu \mathrm{m})$ & Nanostructured $(\mu \mathrm{m})$ \\
\hline Length & 1.997 & 1.657 \\
Variance & 0.285 & 0.153 \\
Diameter & 0.832 & 0.898 \\
Variance & 0.012 & 0.018 \\
\hline
\end{tabular}

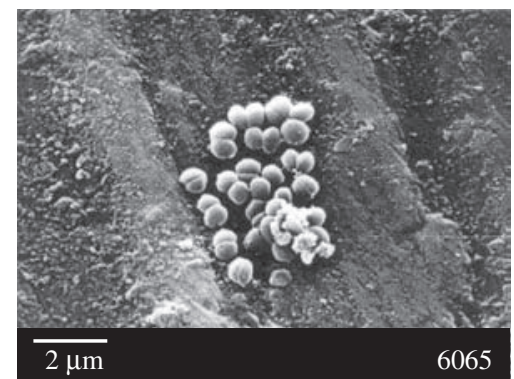

Figure 6. Adhesion of streptococci consortia to rough Ti. a great amount of EPM in the case of Pseudomonas cultures. This increment in the production of polymeric material can be observed comparing Figure 9a, 9b and 9c. The extracellular polymeric material tends to smooth the microroughness of the Si substrate, as has been reported previously ${ }^{7,19}$.

A comparative analysis of the results shows that dissimilar biological response was found on the different substrata used.

In the case of microrough surface of Ti, Streptococci preferentially attach on the valleys.

There was a significant effect of the presence of nanotopography. An important alignment of $P$. fluorescens was observed on nanopatterned Au substratum, where a great amount of isolated bacteria adhered into the trench of the pattern. It was observed a minor amount of microcolonies, and all of them were arranged in direction not parallel to the trench.

It was also observed that on nanostructured $\mathrm{Au}$ there was less production of EPM but more bacterial adhesion than on the control sample. In contrast, microrough Si substrate shows much more production of EPM and less Pseudomonas attachment than on smooth surface. When the parameters that characterize topography and roughness are in the order of bacteria dimension, it was found that bacteria easily adhered and less amount of EPM was produced.

In the case of $\mathrm{Cu}$ samples, the polymeric material was found surrounding and underneath the attached bacteria, maybe, in order

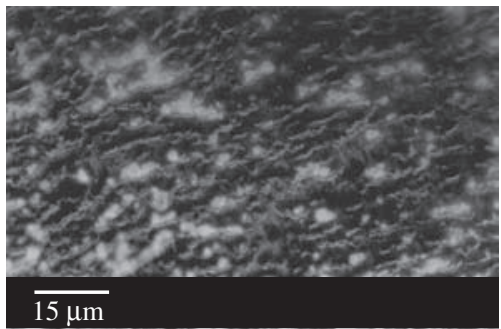

Figure 7. Epifluorescence microscopy corresponding to a rough titanium surface where rows of streptococci with preferential direction can be seen within the valleys.

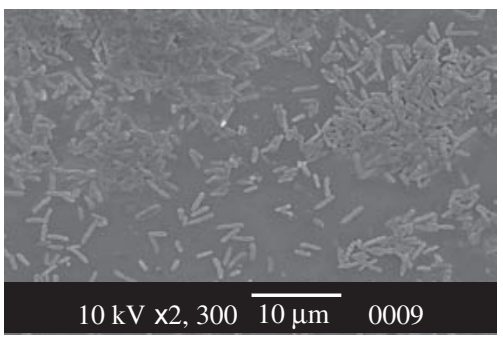

(a)

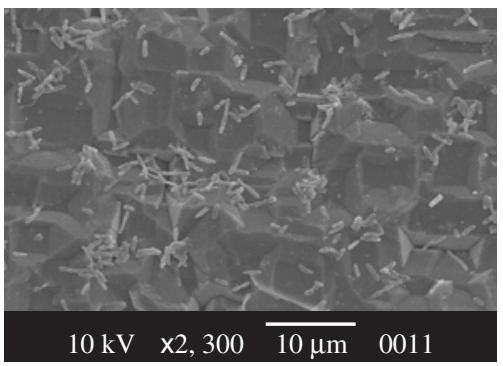

(b)

Figure 8. a) SEM microphotograph of Si smooth surface exposed during 2 hours to $P$ fluorescens culture; and b) SEM microphotograph of Si rough surface exposed during 2 hours to $P$ fluorescens. culture. 


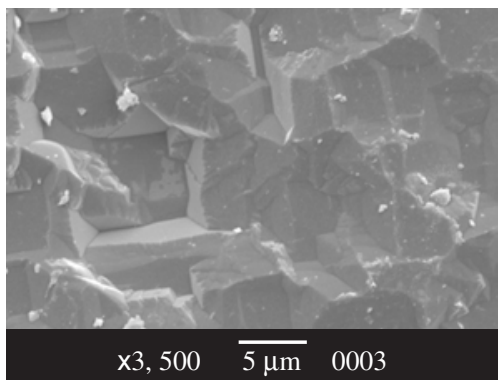

(a)

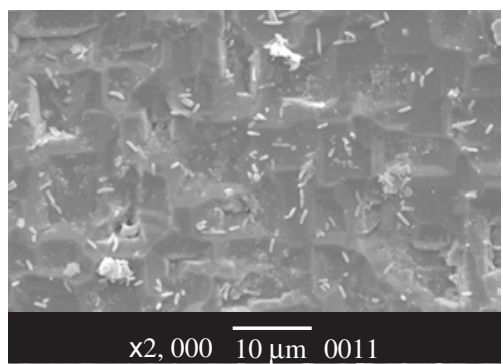

(b)

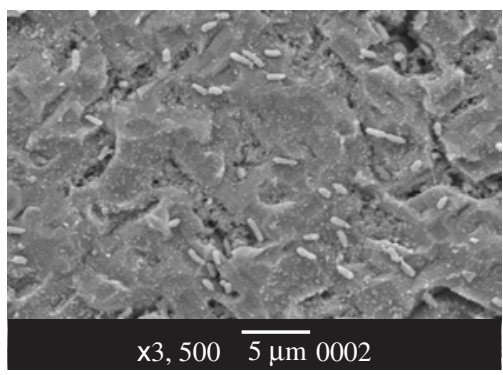

(c)

Figure 9. SEM microphotographs of Si after different exposure periods: a) $\mathrm{t}=0$; b) $\mathrm{t}=30$ minutes; and c) $\mathrm{t}=1$ hour.

to avoid the direct contact with toxic material as shown in Figure 4. The effect of the nature of the surface was strong during the former minutes but was less important at longer periods after the production of abundant EPM. Surfaces properties were severely modified when they were covered by the EPM.

\section{Conclusions}

Surface composition of the substrata, roughness and topography play important roles in the initial stages of biofilm formation.

The initial distribution of bacteria is uneven on smooth surfaces but follows some preferential directions on rough surfaces.

There is a relationship between the roughness characteristic dimension and the bacteria size which affects not only the bacterial attachment but also the production of EPM. When the parameters that characterize topography and roughness are in the order of bacteria dimension, it was found that bacteria easily adhered and less amount of EPM was produced.

It is clear that bacteria act in response to the nanotopography since they chose a preferential direction, changed their morphology and modified the production of EPM under these conditions.

\section{Acknowledgments}

Authors wish to acknowledge the financial support received from UNLP (IO95) and the Agencia Nacional de Promoción Científica y
Tecnológica (PICT 06-12508). S. Gómez de Saravia thanks Commission of Scientific Investigation of Buenos Aires Province CICPBA (I54/06), and PLS and MFLM thanks CONICET (6075/05) for financial support.

\section{References}

1. Castner DG, Ratner BD. Biomedical surface science: Foundations to frontiers. Surface Science. 2002; 500 (1-3):28-60.

2. Stewart PS, Mc Telers GA, Huang C. Biofilm control by antimicrobial agents. In: Bryers J, editor. Biofilm II. Process Analysis and applications, New York: John Wiley \&Sons. 2000. p. 373.

3. Tolker-Nielsen T, Brinch UC, Ragas PC, Andersen JB, Jacobsen CS, Molin S. Development and dynamics of Pseudomonas sp. biofilms. Journal of Bacteriology. 2000; 182(22):6482-6489.

4. Costerton JW, Lewandowski Z, Caldwell DE, Korber DR, LappinScott HM. Microbial biofilms. Annual Review of Microbiology. 1995; 49:711-745

5. Davey ME, O'Toole GO. Microbial biofilms: from ecology to molecular genetics. Microbiology and Molecular Biology Reviews 2000; 64(4):847-867.

6. Mrksich M. What can surface chemistry do for cell biology? Current Opinion Chemical Biology 2002; 6(6):794-797.

7. Cortizo MC, Fernández Lorenzo de Mele M. Microstructural characteristics of thin biofilms through optical and scanning electron microscopy. World Journal of Microbiology and Biotechnology. 2003; 19(8):805-10.

8. Schilardi PL, Azzaroni O, Salvarezza RC. A Novel Application of Alkanethiol Self-Assembled Monolayers in Nanofabrication: Direct Molding and Replication of Patterned Conducting Masters. Langmuir. 2001; 17(9):2748-2752.

9. Fernández Lorenzo de Mele M, Cortizo MC. Biodeterioration of Dental Materials: Influence of Bacterial Adherence; Biofouling. 2000; 14:305-316.

10. Gómez de Saravia SG, Fernández Lorenzo de Mele M, Videla HA. Interaction of biofilms and inorganic passive layers in the corrosion of $\mathrm{Cu} / \mathrm{Ni}$ alloys in chloride environments. Corrosion. 1990; 46(4):302-306.

11. Gómez de Saravia SG, Fernández Lorenzo de Mele M, Videla HA. The interaction of corrosion products and biofouling on 70/30 cupronickel in polluted seawater. Biofouling, 1993; 7:141-155.

12. O'Toole GA, Kaplan H, and Kolter R. Biofilm formation as microbial development. Annual Reviews of Microbiology. 2000a; 54:49-79.

13. Korber DR, Lawrence JR, Caldwell DE. Effect of motility on surface colonization and reproductive success of Pseudomonas Fluorescens in dual dilution continuos and batch culture systems. Applied and Environmental Microbiology. 1994; 60(5):1421-1429.

14. Zobell CE. The effects of solid surfaces upon bacterial activity. Journal of Bacteriology. 1943; 46(1):39-56.

15. Marshall KC, Stout R, Mitchell R. Mechanism of the initial events in the sorption of marine bacteria to surfaces. Journal of General Microbiology. 1971; 68:337-348.

16. van Loodsdrecht MC, Lyklema J, Norde W, Zehnder AJB. Influence of interfaces on microbial activity, Microbiological Reviews. 1990; 54:75-87.

17. Jensen ET, Kharazmi A, Hoiby N, Costerton JW. Some bacterial parameters influencing the neutrophil oxidative burst response to Pseudomonas Aeruginosa biofilms. Apmis. 1992; 100(8):727-733.

18. Fletcher M. Bacterial attachment in aquatic environments: a diversity of surfaces and adhesion strategies. In: Fletcher M. editor. Bacterial adhesion: Molecular and Ecological Diversity. New York: John Wiley \& Sons. 1996. p. 1-24.

19. Zelver N, Roe FL, Characklis WG. Potential for monitoring fouling in the food industry. In: D. Lund, E. Plett, and C. Sander (eds.), Fouling and Cleaning in Food Processing, Madison, WI: Univ. of Wisconsin, Department of Food Science, 1985. p. 255-262. 